\title{
Shuyu capsules relieve liver-qi depression by regulating ERK-CREB-BDNF signal pathway in central nervous system of rat
}

\author{
HONGYAN WANG $^{1 *}$, YINGQUAN ZHANG ${ }^{2 *},{\text { HELOU } \mathrm{LI}^{3}, \mathrm{WEI} \mathrm{ZENG}^{4} \text { and MINGQI QIAO }}^{5}$ \\ ${ }^{1}$ Department of Traditional Chinese Medicine, Taishan Medical University; ${ }^{2}$ Department of Internal Medicine, \\ The Hospital of Traditional Chinese Medicine of Tai'an; Departments of ${ }^{3}$ Laboratory and ${ }^{4}$ Cardiology, \\ Taishan Medical University, Tai'an, Shandong 271000; ${ }^{5}$ Shandong University of \\ Traditional Chinese Medicine, Jinan, Shandong 250355, P.R. China
}

Received June 30, 2017; Accepted September 11, 2017

DOI: 10.3892/etm.2017.5125

\begin{abstract}
The purpose of this study was to investigate the possible therapeutic mechanism of Shuyu capsules in liver-qi depression. Liver-qi depression rats were prepared based on chronic unpredictable mild stress (CUMS) and delayed constraint. Rats were gavaged with Shuyu capsule, fluoxetine, Radix Bupleuri and Radix Paeoniae Alba to constrct rat models. Body weight test, sucrose preference test and open-field test were applied to test rat models. Western blot analysis and quantitative real-time PCR was applied to determine the relative expression of extracellular signal-regulated protein kinase (ERK), cyclic AMP response element binding protein (CREB) and brain-derived neurotrophic factor (BDNF) in hippocampus and frontal lobe tissues. ELISA was used to detect the content of BDNF in serum. Body weight, sugar intake and total distance were significantly decreased in depression group compared with control. The four drugs significantly increased levels of these factors. Compared with control group, ERK, CREB and BDNF expression were significantly decreased in depression group in both hippocampus and frontal lobe tissues at both mRNA and protein level. Shuyu capsule and fluoxetine group showed a significant increase in the expression of ERK, CREB and BDNF at mRNA, p-ERK and p-BDNF at protein level. Compared with Radix Paeoniae Alba, Radix Bupleuri were better in the rescue of ERK, CREB and BDNF expression. In conclusion, the pathogenesis of liver-qi depression associated with lower expression of ERK, CREB and BDNF
\end{abstract}

Correspondence to: Dr Hongyan Wang, Department of Traditional Chinese Medicine, Taishan Medical University, 619 Great Wall Road, Tai'an, Shandong 271000, P.R. China

E-mail: tyi835@163.com

${ }^{*}$ Contributed equally

Key words: Shuyu capsules, depression, ERK-CREB-BDNF signal pathway in hippocampus and frontal. Shuyu capsule and main constitution alleviated the depressive-like behaviors and reversed the disruptions of the p-ERK, p-CREB and BDNF in stressed rats.

\section{Introduction}

Depression disorders are the most severe psychiatric disorders worldwide. The symptoms include retardation of thinking, hypopraxia and downcast mood (1). Many factors are considered to be related with pathogenesis of depression disorder, including internal secretion, nervous system and immune system. Earlier studies presented that liver-qi depression may be related to signal transduction after receptors related to synaptic plasticity, gene transcriptional regulation and target gene expression alteration (2).

Signal transduction system plays a key role in directing signal into cells, and is the target of anti-depression drugs. The pathways involved in depression disorder include cAMP pathway, mitogen-activated protein kinase (MAPK) pathway and CaMK pathway (3-5), of which MAPK pathway plays a key role in the brain-derived neurotrophic factor (BDNF) signal transduction. Extracellular signal-regulated protein kinase (ERK1/2), a number of MAPK family, transmits extracellular stimulus signals into cells, such as neurotransmitter, neurotrophic factors and nerve growth factor $(6,7)$. Besides it involves in pathophysiology of various nervous system diseases by regulating gene expression, synaptic reorganization, axon growth and excitability of neure (8). Phosphorylation of ERK could activate cyclic AMP response element binding protein (CREB), which is an endonuclear regulatory factor, regulating transcription by self-phosphorylation, and playing a key role in regulating and maintaining emotion and memory $(9,10)$. BDNF is a downstream target of CREB, and is a representative number of neurotrophic factors, functioning in hippocampus and frontal lobe tissues by regulating neuroplasticity $(11,12)$. In an earlier study, we found a significant difference of ERK, CREB and BDNF between liver-qi depression rats and normal rats, indicating that ERK-CREB-BDNF pathway may participate in the pathogenesis of liver-qi depression (13). It is more likely a putative treatment target for liver-qi depression. 
The anti-depression drugs can be divided into five groups, including monoamine oxidase inhibitor, tricyclic antidepressant, selective noradrenaline reuptake inhibitor and selective 5-HT reuptake inhibitor. But long-term intake may induce toxic and side-effect and untoward effect. While Chinese medicine in treating depression showed good curative effect and relative lower recurrence rate. Thus, treatment of depression disorder by using Chinese medicine attracts increased attention.

Shuyu capsule is a kind of Chinese medicine developed by our research group, mainly containing active principle from Radix Bupleuri, rhizoma cyperi, Radix Paeoniae Alba and liquorice. It has been studied in a rat model of premenstrual syndrome depression that Shuyu capsules rectified abnormal 5-HT 3 AR and 5- $\mathrm{HT}_{3} \mathrm{BR}$ expression and 5- $\mathrm{HT}_{3}$ channel current changes in a rat model (14). But no pathway alterations was revealed related to depression. Thus in this study, we aimed to analyze the influence on ERK-CREB-BDNF signal pathway of Shuyu capsule and its component.

\section{Materials and methods}

Ethics statement. All animal experiments were approved by the Ethics Committee of Taishan Medical University (Tai'an, China).

Animals and reagents. Healthy Wistar male rats $(\mathrm{n}=48$, $150 \pm 20 \mathrm{~g}$ ) were obtained from Beijing Vital River Laboratory Animal Technology Co., Ltd. (Beijing, China). Rats were housed in animal room at $22 \pm 2{ }^{\circ} \mathrm{C}$. Sterilized diet and water were freely accessed, with an adaptive breeding for 2 weeks. Rats were divided into six groups according to cardinal number of sugar water preference test and open-field test, including control group, model group, Shuyu group, Radix Bupleuri group, fluoxetine group and Radix Paeoniae Alba group, 8 rats in each group.

Shuyu capsule was obtained from Qingdao Haichuang Center for Innovative Biomedical Research (Qingdao, China). Clinical batch no. 2008 L11169. Fluoxetine capsule was obtained from Eli Lilly Suzhou Pharmaceutical Co., Ltd. (Suzhou, China). Clinical batch no. J20100016. Radix Bupleuri extraction and Radix Paeoniae Alba were obtained from Qingdao Haichuang Center for Innovative Biomedical Research.

Sucrose preference test. Sucrose preference test was performed according to Moriyama et al (15). Two drinking spouts (water and $1 \%$ sucrose) were provided to rats after water starvation for $24 \mathrm{~h}$. Bottles were exchanged every $1 \mathrm{~h}$. Sucrose preference was calculated as: Sucrose preference $=$ [sucrose consumption $(\mathrm{ml}) /$ water consumption $(\mathrm{ml})+$ sucrose consumption (ml)] x $100 \%$.

Open-field test. Open-field test was performed according to Zhu et al (16). Before the experiments, rats were allowed an addaptive activity. Rats were placed in the center of the arena, and the activity of rats was recorded, including the number of vertical activity, total journey, the time spend in the center of arena. The total journey was considered as an index of this test.

Stress design. Liver-qi depression rats were prepared based on chronic unpredictable mild stress (CUMS) and delayed constraint $(17,18)$. Depression rats were prepared by providing 2-3 random types of stimulus every day, lasting for 4 weeks. The stimulus included cage inclining $\left(45^{\circ}\right)$, continuous illumination, dirty cage (pouring $200 \mathrm{ml}$ water in cage), empty bottle, limiting food, white noise, strobe light, smell (mothball), foreign matter (block, a strip of cloth), rotation and constraint (four legs restrained by adhesive plaster).

Rats model. Control group rats were prepared without any stimulus, and given a gavage of normal saline $(1 \mathrm{ml} / 200 \mathrm{~g})$. Model group were prepared by giving a gavage of normal saline ( $1 \mathrm{ml} / 200 \mathrm{~g}$ ) to depression rats. Shuyu group was prepared by giving a gavage of Shuyu capsule $(4.08 \mathrm{mg} / \mathrm{kg}$, about 8 -fold dosage of human) to depression rats. Radix Bupleuri group was prepared by giving a gavage of Radix Bupleuri capsule $(4.08 \mathrm{mg} / \mathrm{kg})$ to depression rats. Fluoxetine group was prepared by giving a gavage of fluoxetine $(0.72 \mathrm{mg} / \mathrm{kg} / \mathrm{day})$ to depression rats. Radix Paeoniae Alba group was prepared by giving a gavage of Radix Paeoniae Alba (36 mg/kg/day) to depression rats.

Model evaluation and sampling. Rats were anesthetized using $3 \%$ chloral hydrate $(0.3 \mathrm{ml} / 100 \mathrm{~g})$. Blood was obtained from ostcava, half was stored in Ep tubes treated with heparin in advance. The rest blood was centrifuged at $1200 \mathrm{x} \mathrm{g}, 4^{\circ} \mathrm{C}$ for separating serum. All samples were stored at $-70^{\circ} \mathrm{C}$.

Western blot analysis and ELISA. Blood was obtained from ostcava after rats were anesthetized using 3\% chloral hydrate $(0.3 \mathrm{ml} / 100 \mathrm{~g})$. Hippocampus and frontal lobe tissues were obtained from head after rats were sacrificed. All samples were stored at $-70^{\circ} \mathrm{C}$.

Western blot analysis was performed according to standard protocols. Total protein was extracted using RIPA lysate. Protein concentration was measured with BCA protein assay kit (Pierce, Bonn, Germany) according to the manufacturer's instructions. Total cellular proteins were separated by 10\% SDS-PAGE and transferred onto nitrocellulose membranes (EMD Millipore, Billerica, MA, USA). After blocking in $5 \%$ skim milk for $1 \mathrm{~h}$, the membranes were incubated with primary antibodies ( $\beta$-actin, A1978, 1:2,000; Sigma-Aldrich, St. Louis, MO, USA) (ERK, cat. no. 9102, 1:2,000; p-ERK, cat. no. 9101, 1:2,000; CREB, cat. no. 9197, 1:150; P-CREB, cat. no. 9191, 1:150; all from Cell Signaling Technology, Inc., Danvers, MA, USA) (BDNF, cat. no. ab108383, 1:1,200; Abcam, Cambridge, MA, USA) overnight at $4^{\circ} \mathrm{C}$, followed by the incubation with goat anti-rabbit secondary antibodies (ERK, 1:2,000; CREB 1:150; BDNF 1:1,200) for $2 \mathrm{~h}$ at room temperature. Protein bands were visualized on X-ray film using enhanced chemiluminescence ECL substrate (Pierce).

The levels of BDNF were detected with enzyme-linked immunosorbent assay (ELISA) according to the manufacturer's instruction.

Quantitative-real time PCR. Total RNA was extracted using TRIzol reagent (Invitrogen, Carlsbad, CA, USA). The cDNA was synthesized from RNA samples using a RevertAid First-Strand cDNA Synthesis kit (Takara, Dalian, China). 
qRT-PCR was performed with SYBR Premix ExTaq (Takara) with a LightCycler 480 apparatus (Roche Molecular Systems, Inc., Pleasanton, CA, USA). $\beta$-actin was used for internal control. The relative expression of genes was calculated by $2^{-\triangle \Delta \mathrm{Cq}}$ method. The sequences of primers were: ERK forward, 5'-GTGAAGTTCATTTCCAATCCGC-3' and reverse, 5'-GGGACATCACCCTCACTTAC-3'; CREB forward, 5'-CCATCCACTCCTGTGTCATCT-3' and reverse, 5'-CCTTGTAAATCCTCTTCCATCA-3'; BDNF forward, 5'-CACCCGCGAGTACAACCTTC-3' and reverse, 5'-CCCA TACCCACCATCACACC-3'.

Statistical analysis. Statistical analysis was performed using GraphPad Prism 5 (GraphPad Software, San Diego, CA, USA). All data are presented as mean $\pm \mathrm{SD}$. A value with $\mathrm{P}<0.05$ indicated statistically significant difference.

\section{Results}

Body weight analysis. Body weight was measured once a week after model rats were made, as shown in Fig. 1. In week 4, body weights were significantly decreased in liver-qi depression model rats $(\mathrm{P}<0.01)$ in comparison with control group, but no significance were found in drug group (Table I). Compared with depression model group, body weights were significantly increased in Shuyu group and fluoxetine group $(\mathrm{P}<0.01)$, and no significant difference was found in Radix Paeoniae Alba group and Radix Bupleuri group.

Sugar preference test. Sugar consumption was tested once a week in the six groups (Fig. 2). In week 4, sugar consumption was significantly decreased in depression group in comparison with normal control $(\mathrm{P}<0.05)$, and significant increase was found in drug groups in comparison with depression group $(\mathrm{P}<0.01)$, indicating that depression rats lacked pleasant sensation, which could be improved by fluoxetine, Shuyu capsule, Radix Bupleuri extraction and Radix Paeoniae Alba extraction (Table II).

Open-field test. Total journey of rats in open-field was recorded once a week (Fig. 3). In week 4, total journey in depression group was significantly decreased compared with control group $(\mathrm{P}<0.01)$, and no significant difference were found in drug groups (Table III). Compared with depression group, total journey in fluoxetine group $(\mathrm{P}<0.01)$, Shuyu group $(\mathrm{P}<0.01)$ and Radix Bupleuri group $(\mathrm{P}<0.05)$ was significantly increased, while no significant increase was found in Radix Paeoniae Alba group.

Detection of ERK, BDNF and CREB in hippocampus and frontal lobe tissues. Expression levels of BDNF, ERK and CREB in hippocampus and frontal lobe tissues were detected at both mRNA and protein levels.

ERK expression. ERK expression was detected in hippocampus and frontal lobe tissues in all groups. In hippocampus tissues (Fig. 4A and B), ERK expression was significantly decreased compared with control group $(\mathrm{P}<0.05)$ at both mRNA and protein level. After gavaged with Shuyu capsule or fluoxetine, ERK expression was significantly increased $(\mathrm{P}<0.01)$, nearly to the normal group. Although in Radix
Table I. Comparison of weight (mean \pm SD) in rats in week 4 .

\begin{tabular}{lcc}
\hline Group & Before modeling & After modeling \\
\hline Control group & $172.7 \pm 2.215$ & $258.7 \pm 4.030$ \\
Depression model group & $170.1 \pm 2.493$ & $225.7 \pm 3.290^{\mathrm{a}}$ \\
Shuyu group & $174.2 \pm 1.914$ & $251.3 \pm 4.882^{\mathrm{b}}$ \\
Fluoxetine group & $175.0 \pm 2.270$ & $252.1 \pm 5.692^{\mathrm{b}}$ \\
Radix Bupleuri group & $170.5 \pm 3.312$ & $245.3 \pm 4.393^{\mathrm{c}}$ \\
Radix Paeoniae Alba group & $169.8 \pm 4.704$ & $244.3 \pm 6.218^{\mathrm{c}}$ \\
\hline
\end{tabular}

${ }^{\mathrm{a}}$ Compared with control group, significant difference was $\mathrm{P}<0.01$. ${ }^{\mathrm{b}} \mathrm{Compared}$ with depression model group, there was significant difference, $\mathrm{P}<0.01$ and ${ }^{\mathrm{c}}$ compared with depression model group, there was significant difference, $\mathrm{P}<0.05$.

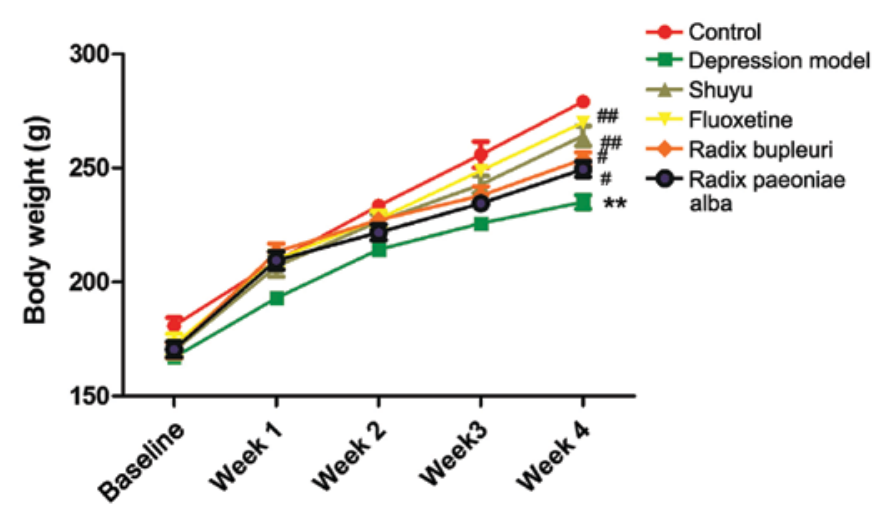

Figure 1. Body weight comparison. Body weight was significantly decreased in depression models compared with control group $(\mathrm{P}<0.01)$. Compared with depression models, there is significant increase in the drug groups $(\mathrm{P}<0.05)$ ${ }^{\#}$ Compared with depression models, $\mathrm{P}<0.05$. ${ }^{\# \# C o m p a r e d ~ w i t h ~ d e p r e s s i o n ~}$ models, $\mathrm{P}<0.01$. $^{* *}$ Compared with control group, $\mathrm{P}<0.01$.

Bupleuri group and Radix Paeoniae Alba group ERK expression was increased, it was still less than it in control group $(\mathrm{P}<0.05)$. In frontal lobe tissues (Fig. 4C and D), similar results were obtained, except for the Radix Bupleuri group and Radix Paeoniae Alba group. No significant difference was found in the two groups compared with depression model group.

$B D N F$ expression. BDNF expression was detected in hippocampus and frontal lobe tissues in all groups. In hippocampus tissues (Fig. 5A and B), BDNF expression was significantly decreased compared with control group $(\mathrm{P}<0.01)$ at both mRNA and protein level. After gavaged with Shuyu capsule or fluoxetine, BDNF expression was significantly increased $(\mathrm{P}<0.01)$, and in Radix Bupleuri group and Radix Paeoniae Alba group, it was also increased $(\mathrm{P}<0.05)$. In frontal lobe tissues (Fig. 5C and D), similar results were obtained, except for the Radix Bupleuri group and Radix Paeoniae Alba group. No significant difference was found in the two groups compared with depression model group.

$C R E B$ expression. CREB expression was detected in hippocampus and frontal lobe tissues in all groups. In hippocampus tissues (Fig. 6A and B), CREB expression was significantly decreased compared with control group $(\mathrm{P}<0.01)$ at both mRNA and protein level. After gavaged with 
Table II. Sugar consumption was tested in week 4 (mean \pm SD).

\begin{tabular}{lcc}
\hline Groups & Before modeling & After modeling \\
\hline Control group & $0.8137 \pm 0.02404$ & $0.8755 \pm 0.02270$ \\
Depression model group & $0.7822 \pm 0.04440$ & $0.5507 \pm 0.04922^{\mathrm{a}}$ \\
Shuyu group & $0.7992 \pm 0.01608$ & $0.8182 \pm 0.04202^{\mathrm{b}}$ \\
Fluoxetine group & $0.7734 \pm 0.03438$ & $0.8329 \pm 0.02393^{\mathrm{b}}$ \\
Radix Bupleuri group & $0.7902 \pm 0.02464$ & $0.7652 \pm 0.02632^{\mathrm{b}}$ \\
Radix Paeoniae Alba group & $0.7760 \pm 0.04704$ & $0.7930 \pm 0.02401^{\mathrm{b}}$
\end{tabular}

${ }^{\mathrm{a}}$ Compared with control group, there was significant difference, $\mathrm{P}<0.01 .{ }^{\mathrm{b}} \mathrm{Com}-$ pared with depression model group, there was significant difference, $\mathrm{P}<0.01$.

Table III. Total journey of rats in open-field test.

\begin{tabular}{lcc} 
Groups & Before modeling & After modeling \\
\hline Control group & $13,327 \pm 756.5$ & $9,786 \pm 654.8$ \\
Depression model group & $12,585 \pm 801.2$ & $5,447 \pm 356.4^{\mathrm{a}}$ \\
Shuyu group & $12,732 \pm 669.1$ & $9,320 \pm 531.9^{\mathrm{b}}$ \\
Fluoxetine group & $13,073 \pm 810.2$ & $9,646 \pm 718.6^{\mathrm{b}}$ \\
Radix Bupleuri group & $12,336 \pm 980.8$ & $9,057 \pm 643.0^{\mathrm{c}}$ \\
Radix Paeoniae Alba group & $13,097 \pm 794.3$ & $9,024 \pm 589.4$ \\
\hline
\end{tabular}

${ }^{\mathrm{a} C}$ Compared with control group, there was significant difference, $\mathrm{P}<0.01$. ${ }^{\mathrm{b}}$ Compared with depression model group, there was significant difference, $\mathrm{P}<0.01$, and ${ }^{\mathrm{C}} \mathrm{P}<0.05$.

Table IV. Concentration of BDNF in peripheral blood.

\begin{tabular}{lc}
\hline Groups & Concentration $(\mathrm{ng} / \mathrm{ml})$ \\
\hline Control group & $162.3 \pm 14.54$ \\
Depression model group & $116.5 \pm 4.627^{\mathrm{a}}$ \\
Shuyu group & $161.6 \pm 8.025^{\mathrm{b}}$ \\
Fluoxetine group & $161.34 \pm 8.286^{\mathrm{b}}$ \\
Radix Bupleuri group & $158.8 \pm 6.206^{\mathrm{b}}$ \\
Radix Paeoniae Alba group & $161.1 \pm 6.764^{\mathrm{b}}$ \\
\hline
\end{tabular}

${ }^{\mathrm{a} C o m p a r e d ~ w i t h ~ c o n t r o l ~ g r o u p, ~ t h e r e ~ w a s ~ s i g n i f i c a n t ~ d i f f e r e n c e, ~} \mathrm{P}<0.05$. ${ }^{\mathrm{b} C o m p a r e d}$ with depression model group, there was significant difference, $\mathrm{P}<0.05$. BDNF, brain-derived neurotrophic factor.

Shuyu capsule $(\mathrm{P}<0.01)$ fluoxetine $(\mathrm{P}<0.01)$, Radix Bupleuri $(\mathrm{P}<0.05)$ or Radix Paeoniae Alba $(\mathrm{P}<0.05)$, BDNF expression was significantly increased at mRNA level. At protein level (Fig. 6B), Shuyu capsule $(\mathrm{P}<0.01)$ fluoxetine $(\mathrm{P}<0.01)$, Radix Bupleuri $(\mathrm{P}<0.05)$ showed a significant increase of p-CREB/CREB. In frontal lobe group, all the drug groups showed significant increase of CREB compared with depression model group at mRNA level (Fig. 6C). At protein level, only Radix Paeoniae Alba group didn't present significant increase of p-CREB/CREB (Fig. 6D).

BDNF concentration in peripheral blood. BDNF concentration was detected in peripheral blood of all groups using

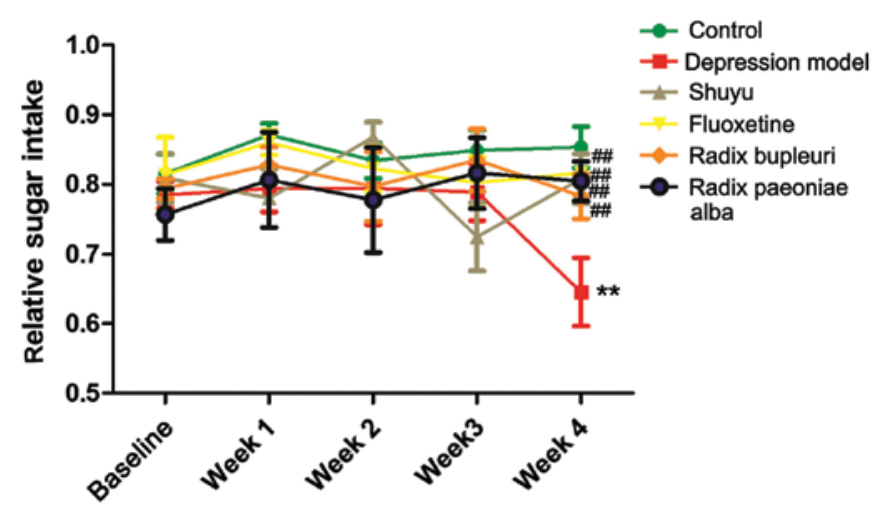

Figure 2. Sugar preference test. Compared with control group, sugar intake was significantly decreased in depression models $(\mathrm{P}<0.01)$. Compared with depression models, sugar intake was significantly increased in all the drug groups $(\mathrm{P}<0.01)$. ${ }^{* *}$ Compared with control group, $\mathrm{P}<0.01$. ${ }^{\# \# C o m p a r e d ~ w i t h ~}$ depression models, $\mathrm{P}<0.01$

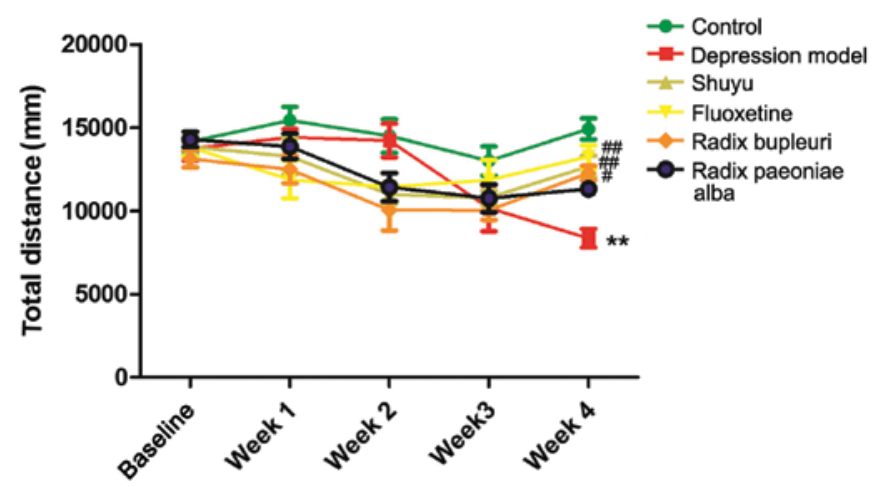

Figure 3. Total distance test. Depression models showed significantly decreased total distance $(\mathrm{P}<0.01)$. Except for Radix Paeoniae Alba, the other three drugs significantly increased total distance $(\mathrm{P}<0.05) .{ }^{* *}$ Compared with control group, $\mathrm{P}<0.01 .{ }^{\#}$ Compared with depression models, $\mathrm{P}<0.05$. ${ }^{\# \#}$ Compared with depression models, $\mathrm{P}<0.01$.

ELISA. Compared with normal control, BDNF concentration was significantly decreased in depression rats $(\mathrm{P}<0.05)$, and it was significantly increased in the four drug groups compared with depression model group $(\mathrm{P}<0.05)$ (Table IV).

\section{Discussion}

CUMS is a typical method to construct liver-qi depression models (19). In this study, we constructed liver-qi depression rat models by combining CUMS and delayed constraint stimulus. In the procedures, rats were randomly given several stimuli, which was similar with human depression formation mechanism (20).

In this study, we applied open-field test, weight and sucrose preference test to evaluate depression rat models, of which open-field test is the most important method to detect rats' excitability and environmental adaptation (21). Open-field test showed that total journal of depression models were significantly decreased compared with control group, and it was significantly increased in all the drug groups. These findings indicated that Shuyu capsule and its component may effectively increased adaptive capacity and excitability in depression rats. 
A

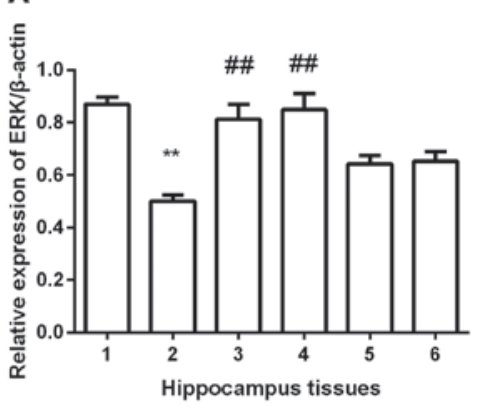

B

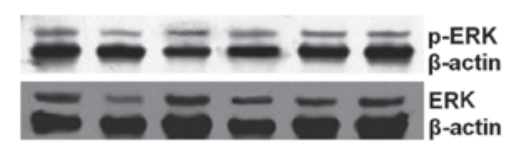

C

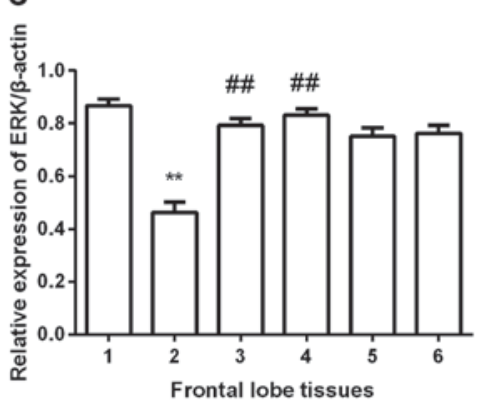

D
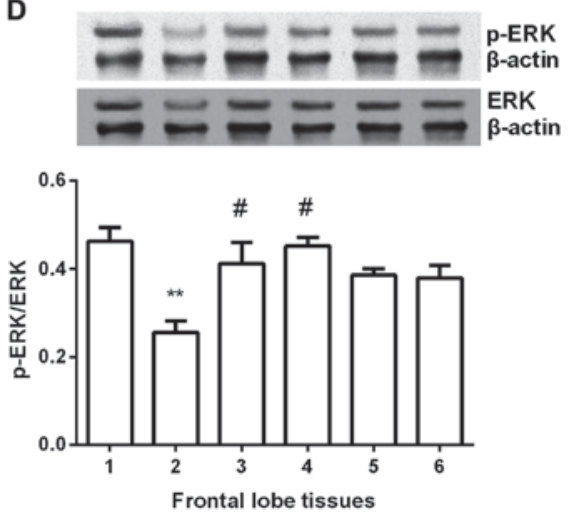

Figure 4. Expression of ERK in hippocampus and prefrontal cortex tissues. ERK expression was significantly decreased in depression group (P<0.01) and Shuyu capsule and fluoxetine significantly increased ERK expression at mRNA level (A and C). Western blot analysis showed that p-ERK/ERK was significantly decreased and Shuyu capsule and fluoxetine significantly increased p-ERK/ERK in both tissues (P<0.05) (B and D). Radix Bupleuri and Radix Paeoniae Alba significantly increased p-ERK/ERK only in hippocampus tissues $(\mathrm{P}<0.05)(\mathrm{B}) .{ }^{* *}$ Compared with control group, $\mathrm{P}<0.01$. ${ }^{*} \mathrm{Compared}$ with depression models, $\mathrm{P}<0.05$. ${ }^{\# \#}$ Compared with depression models, $\mathrm{P}<0.01$. ERK, extracellular signal-regulated protein kinase; p-, phosphorylated; 1 , control group; 2 , depression group; 3, Shuyu group; 4, fluoxetine group; 5, Radix Bupleuri; 6, Radix Paeoniae Alba.

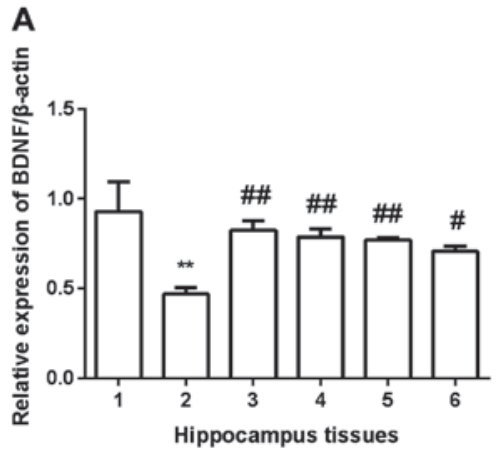

B
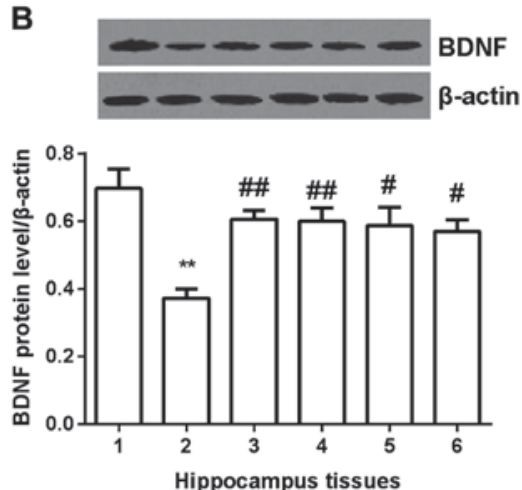

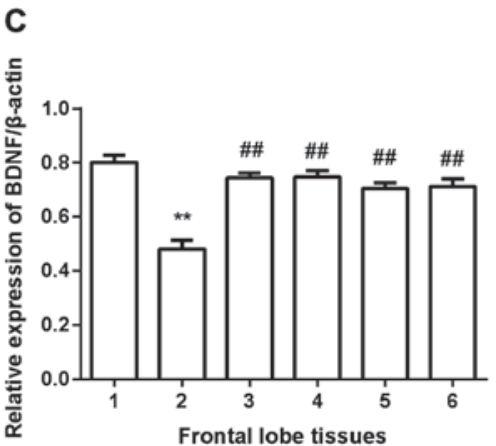

D
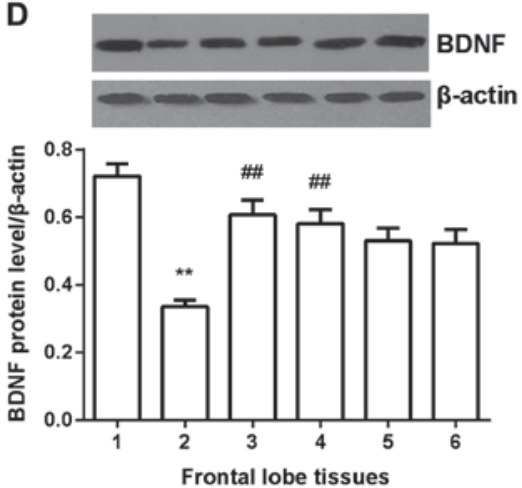

Figure 5. Expression of BDNF in hippocampus and prefrontal cortex tissues. BDNF expression was significantly decreased at both mRNA and protein level. All the drugs significantly increased BDNF expression at mRNA level (A and C). At protein level, in hippocampus tissues, all the four drugs significantly increased BDNF expression (B), but in prefrontal cortex tissues, only Shuyu capsule and fluoxetinem significantly increased BDNF expression (D). ${ }^{* *}$ Compared with control group, $\mathrm{P}<0.01$. " Compared with depression models, $\mathrm{P}<0.05$. ${ }^{\#}$ Compared with depression models, $\mathrm{P}<0.01$. BDNF, brain-derived neurotrophic factor; 1, control group; 2, depression group; 3, Shuyu group; 4, fluoxetine group; 5, Radix Bupleuri; 6, Radix Paeoniae Alba. 


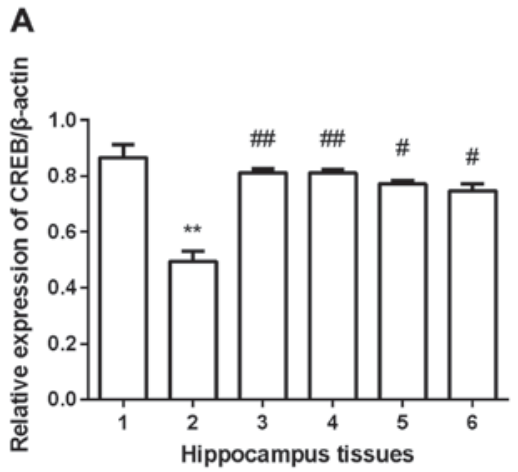

B
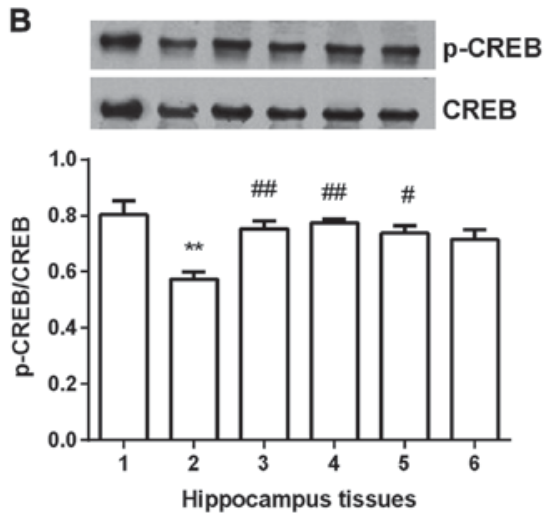

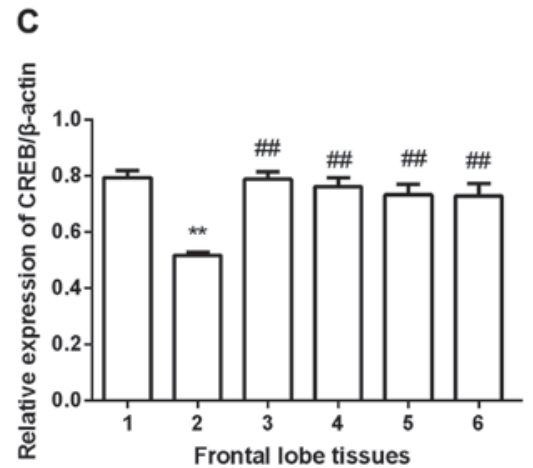

D
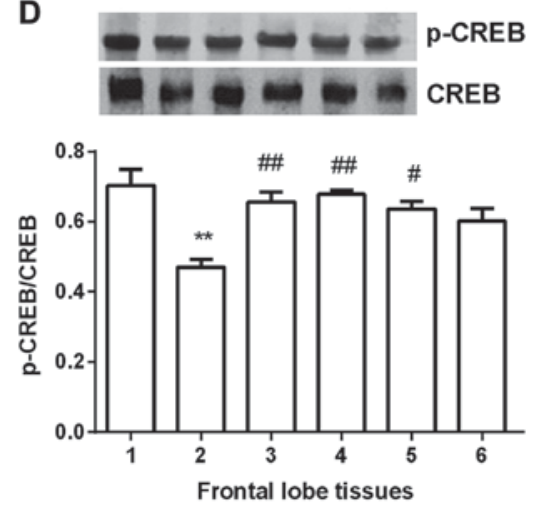

Figure 6. Expression of CREB in hippocampus and prefrontal cortex tissues. At mRNA level, CREB expression was significantly decreased in depression group compared with depression group and all the four drugs significantly increased its expression (A and C). Western blot analysis showed that p-CREB/CREB was significantly decreased in depression group compared with control group, and only Radix Paeoniae Alba did not significantly increase p-CREB/CREB (B and D). ${ }^{* *}$ Compared with control group, $\mathrm{P}<0.01$. ${ }^{*}$ Compared with depression models, $\mathrm{P}<0.05$. ${ }^{\#}$ Compared with depression models, $\mathrm{P}<0.01$. CREB, cyclic AMP response element binding protein; p-, phosphorylated; 1, control group; 2, depression group; 3, Shuyu group; 4, fluoxetine group; 5, Radix Bupleuri; 6 , Radix Paeoniae Alba.

Although fluoxetine dramatically increased adaptive capacity and excitability in rats, long-term medication may induce overexcitation in central nervous system (22).

Food-intake and digestion of rats were detected by weight. Many depression patients showed decreased appetite and digestion ability, thus it is an important index in evaluating depression rats. In this study, weight increment in depression models was significantly decreased compared to other groups $(\mathrm{P}<0.05)$, indicating that depression rats showed obviously decreased appetite, but fluoxetine and Shuyu capsule effectively improved the situation.

Sucrose preference test was used to detect pleasant sensation of rats. The preference coefficient is low when pleasant sensation to environment is lost (23). In the present study, sucrose preference in drug groups was significantly increased compared with depression rats, indicating that capsules and components showed effective performance in increasing of pleasant sensation.

The mechanism of depression is closely associated to the central nervous system. In this study, we chose hippocampus and frontal lobe as subject due to the two districts regulating motion and behavioristics via variety of pathways (24). According to the posthumous autopsy report of depression patients, hippocampus was atrophy to some extent (25). Earlier study showed that hippocampus and fascia dentata volume was much smaller in patients with Alzheimer disease compared with normal samples, which suggested that the shrinking of hippocampus induced cognitive function obstacle, resulting in depression (26). Prefrontal cortex functions importantly in the emotion process as it is found that left prefrontal cortex compensatory conducting emotion stimulus in the analysis of magnetoencephalogram in depression patients. Magnetic stimulation interference across cranium showed that prefrontal lobe provided attention in the coding and extracting memory (27). Thus prefrontal lobe performs important roles in regulation of emotion and cognitive function.

ERK belongs to the MAPK family, which participates in the physiology activity, including signal transmission and recognition, cell growth and development, and proliferation (28). Signals are transmitted through MAPK signal pathway via three kinase cascades. ERK pathway is the classical MAPK signal pathway, and the reaction chain mainly consists of three protein kinases. ERK pathway regulates cell proliferation, differentiation or apoptosis through the Ras/Raf/MEK/ERK pathway $(29,30)$. In this study, we found that expression of ERK was significantly lower than other groups at both mRNA and protein level, which suggested that liver-qi depression disorder may be related to the lower expression of ERK.

CREB is widely distributed in hippocampus and cerebral cortex (31). Dephosphorylation of CREB means it has no transcriptional activity. CREB is phosphorylated if signals stimulate and recognize the corresponding site of CREB and then activate target gene transcription. CREB-defective rats showed dysfunction in neure plasticity in mice, mainly in the memory function related with auditory sense (32). Dysmnesia is improved after endogenous CREB expression is increased, 
indicating that CREB could obviously promote nerve excitability caused by cerebral injury (33). In this study, CREB expression was significantly decreased in depression group. It is increased in Shuyu group, fluoxetine grop and Radix Bupleuri group nearly to the normal level. It is suggested that these three drugs increased CREB expression and showed anti-depression effect by improving depression, emotion and behavior.

BDNF is a member of neurotrophic factor family. Earlier study showed that long-term chronic stress could reduce BDNF level in cerebrum limbic system, and further induce atrophy of hippocampus and prefrontal cortex (34). BDNF functions in the nerve-protective and anti-depression mechanism by promoting hippocampus proliferation and differentiation via TrkB regulation, and by increasing antioxidase and scavenging free radical (35). BDNF is also found in peripheral nervous system, which may be related to the ability of across hemato-encephalic barrier. In depression patients and rats, BDNF expression is decreased and can be rescued by anti-depression drugs, indicating that BDNF may be the target of anti-depression drugs, but it is uncertain. In this study, we identified BDNF expression was significantly decreased in depression rats compared with normal control. The expression was rescued when rats were gavaged with drugs. Thus we suggested that anti-depression drugs exerts anti-depression function by increasing BDNF expression at both mRNA and protein level.

In this study, fluoxetine, Shuyu capsule, Radix Paeoniae Alba and Radix Bupleuri were used to detect the effect on depression rats. Radix Paeoniae Alba and Radix Bupleuri are two mainly components in capsule. Radix Bupleuri showed effective promotion on the expression of ERK, CREB and BDNF, indicating that it is the main effective constituent.

There are some limitations in this study: i) In addition to hippocampus and prefrontal cortex tissues, inferior colliculus, amygdaloid nucleus and corpus striatum also involved in the regulation of depression. Further study is needed to investigate on these encephalic regions. ii) We prepared liver-qi depression models by combining CUMS and delayed constraint. Classic evaluation method can be used on depression model, but there is still controversy in evaluating liver- $q i$ depression model. iii) To investigate the active composition, we analyzed the effect of Radix Bupleuri and Radix Paeoniae Alba on depression rats, but did not extract the effective monomer, which still needs more research.

\section{Acknowledgements}

The present study was supported by the National Natural Youth Foundation of China (81202620).

\section{References}

1. Zandio M, Ferrín M and Cuesta MJ: Neurobiology of depression An Sist Sanit Navar 25 (Suppl 3): 43-62, 2002 (In Spanish).

2. Bremner JD, Vythilingam M, Vermetten E, Vaccarino V and Charney DS: Deficits in hippocampal and anterior cingulate functioning during verbal declarative memory encoding in midlife major depression. Am J Psychiatry 161: 637-645, 2004.

3. Marsden WN: Synaptic plasticity in depression: Molecular, cellular and functional correlates. Prog Neuropsychopharmacol Biol Psychiatry 43: 168-184, 2013.

4. Kratz AL, Ehde DM and Bombardier $\mathrm{CH}$ : Affective mediators of a physical activity intervention for depression in multiple sclerosis. Rehabil Psychol 59: 57-67, 2014.
5. Qi X, Lin W, Li J, Li H, Wang W, Wang D and Sun M: Fluoxetine increases the activity of the ERK-CREB signal system and alleviates the depressive-like behavior in rats exposed to chronic forced swim stress. Neurobiol Dis 31: 278-285, 2008.

6. Alboni S, Benatti C, Capone G, Corsini D, Caggia F, Tascedda F, Mendlewicz $\mathrm{J}$ and Brunello N: Time-dependent effects of escitalopram on brain derived neurotrophic factor (BDNF) and neuroplasticity related targets in the central nervous system of rats. Eur J Pharmacol 643: 180-187, 2010.

7. Kumamaru E, Numakawa T, Adachi N, Yagasaki Y, Izumi A, Niyaz M, Kudo M and Kunugi H: Glucocorticoid prevents brain-derived neurotrophic factor-mediated maturation of synaptic function in developing hippocampal neurons through reduction in the activity of mitogen-activated protein kinase. Mol Endocrinol 22: 546-558, 2008

8. Xu H, Steven Richardson J and Li XM: Dose-related effects of chronic antidepressants on neuroprotective proteins $\mathrm{BDNF}, \mathrm{Bcl}-2$ and $\mathrm{Cu} / \mathrm{Zn}-\mathrm{SOD}$ in rat hippocampus. Neuropsychopharmacology 28: 53-62, 2003.

9. Bilecki W, Wawrzczak-Bargiela A and Przewlocki R: Activation of AP-1 and CRE-dependent gene expression via mu-opioid receptor. J Neurochem 90: 874-882, 2004.

10. Walters CL, Cleck JN, Kuo YC and Blendy JA: Mu-opioid receptor and CREB activation are required for nicotine reward. Neuron 46: 933-943, 2005.

11. Ligeza A, Wawrzczak-Bargiela A, Kaminska D, Korostynski M and Przewlocki R: Regulation of ERK1/2 phosphorylation by acute and chronic morphine - implications for the role of cAMP-responsive element binding factor (CREB)-dependent and Ets-like protein-1 (Elk-1)-dependent transcription; small interfering RNA-based strategy. FEBS J 275: 3836-3849, 2008.

12. Tiraboschi E, Tardito D, Kasahara J, Moraschi S, Pruneri P, Gennarelli M,Racagni G and Popoli M: Selective phosphorylation of nuclear CREB by fluoxetine is linked to activation of CaM kinase IV and MAP kinase cascades. Neuropsychopharmacology 29: 1831-1840, 2004.

13. Enjeti AK, D'Crus A, Melville K, Verrills NM and Rowlings P: A systematic evaluation of the safety and toxicity of fingolimod for its potential use in the treatment of acute myeloid leukaemia. Anticancer Drugs 27: 560-568, 2016.

14. Li F, Feng J, Gao D, Wang J, Song C, Wei S and Qiao M: Shuyu capsules relieve premenstrual syndrome depression by reducing 5-HT3AR and 5-HT3BR expression in the rat brain. Neural Plast 2016: 7950781, 2016.

15. Moriyama Y, Takagi $\mathrm{N}$ and Tanonaka $\mathrm{K}$ : Intravenous injection of neural progenitor cells improved depression-like behavior after cerebral ischemia. Transl Psychiatry 1: e29, 2011.

16. Zhu X, Li T, Peng S, Ma X, Chen X and Zhang X: Maternal deprivation-caused behavioral abnormalities in adult rats relate to a non-methylation-regulated D2 receptor levels in the nucleus accumbens. Behav Brain Res 209: 281-288, 2010.

17. Zhang L, Luo J, Zhang M, Yao W, Ma X and Yu SY: Effects of curcumin on chronic, unpredictable, mild, stress-induced depressive-like behaviour and structural plasticity in the lateral amygdala of rats. Int J Neuropsychopharmacol 17: 793-806, 2014.

18. Wang SS, Wang YG, Chen HY, Wu ZP and Xie HG: Expression of genes encoding cytokines and corticotropin releasing factor are altered by citalopram in the hypothalamus of post-stroke depression rats. Neuro Endocrinol Lett 34: 773-779, 2013.

19. Banasr M, Valentine GW, Li XY, Gourley SL, Taylor JR and Duman RS: Chronic unpredictable stress decreases cell proliferation in the cerebral cortex of the adult rat. Biol Psychiatry 62: 496-504, 2007.

20. Taksande BG, Faldu DS, Dixit MP, Sakaria JN, Aglawe MM, Umekar MJ and Kotagale NR: Agmatine attenuates chronic unpredictable mild stress induced behavioral alteration in mice. Eur J Pharmacol 720: 115-120, 2013.

21. Tsunoda M, Sugaya C, Sugiura Y, Nagai Y and Sakanishi K: Safety evaluation of self-assembling peptide gel after intracranial administration to rats using the open field test. Biol Pharm Bull 39: 1419-1423, 2016.

22. Szasz BK, Mike A, Karoly R, GerevichZ,Illes P, Vizi ES and Kiss JP: Direct inhibitory effect of fluoxetine on N-methyl-D-aspartate receptors in the central nervous system. Biol Psychiatry 62: 1303-1309, 2007.

23. Wang HN, Wang L, Zhang RG, Chen YC, Liu L, Gao F, Nie H, Hou WG, Peng ZW and Tan Q: Anti-depressive mechanism of repetitive transcranial magnetic stimulation in rat: The role of the endocannabinoid system. J Psychiatr Res 51: 79-87, 2014. 
24. Wu HF, Zhu CH and Guo JY: Effect of ginsenoside Rg1 on behaviors and hippocampal amino acids in depressive-like rats. Zhongguo Zhong Yao Za Zhi 37: 3117-3121, 2012 (In Chinese).

25. McEwen BS: Stress and hippocampal plasticity. Annu Rev Neurosci 22: 105-122, 1999.

26. Fu AK, Hung KW, Huang H, Gu S, Shen Y, Cheng EY, Ip FC, Huang X, Fu WY and Ip NY: Blockade of EphA4 signaling ameliorates hippocampal synaptic dysfunctions in mouse models of Alzheimer's disease. Proc Natl Acad Sci USA 111: 9959-9964, 2014.

27. Dudkin KN, Chueva IV and Makarov FN: The role of the prefrontal and parietal cortex in learning and memory in monkeys. Ross Fiziol Zh Im I M Sechenova 86: 1458-1470, 2000 (In Russian).

28. Drevets WC: Functional neuroimaging studies of depression: The anatomy of melancholia. Annu Rev Med 49: 341-361, 1998.

29. McCubrey JA, Steelman LS, Chappell WH, Abrams SL, Wong EW, Chang F, Lehmann B, Terrian DM, Milella M, Tafuri A, et al: Roles of the Raf/MEK/ERK pathway in cell growth, malignant transformation and drug resistance. Biochim Biophys Acta 1773 : $1263-1284,2007$

30. Chang F, Steelman LS, Lee JT, Shelton JG, Navolanic PM, Blalock WL, Franklin RA and McCubrey JA: Signal transduction mediated by the Ras/Raf/MEK/ERK pathway from cytokine receptors to transcription factors: Potential targeting for therapeutic intervention. Leukemia 17: 1263-1293, 2003.
31. Mantamadiotis T, Lemberger T, Bleckmann SC, Kern H, Kretz O, Martin Villalba A, Tronche F, Kellendonk C, Gau D, Kapfhammer J, et al: Disruption of CREB function in brain leads to neurodegeneration. Nat Genet 31: 47-54, 2002.

32. Lonze BE and Ginty DD: Function and regulation of CREB family transcription factors in the nervous system. Neuron 35: 605-623, 2002

33. Yiu AP, Mercaldo V, Yan C, Richards B, Rashid AJ, Hsiang HL, Pressey J, Mahadevan V, Tran MM, Kushner SA, et al: Neurons are recruited to a memory trace based on relative neuronal excitability immediately before training. Neuron 83: 722-735, 2014.

34. Hetman M and Gozdz A: Role of extracellular signal regulated kinases 1 and 2 in neuronal survival. Eur J Biochem 271: 2050-2055, 2004.

35. Sun ZG, Huang QZ, Xu CY and Chen LP: Effects of shuyu ningxln recipe on the praxiology and the expressions of hippocampal BDNF and trkB of model rats with chronic stress-induced depression. Zhongguo Zhong Xi Yi Jie He Za Zhi 33: 370-375, 2013 (In Chinese). 